\title{
Associate Professor Brendon Yee: it is a two-way street in terms of treating obesity and sleep apnoea
}

Submitted Jul 27, 2018. Accepted for publication Aug 07, 2018.

doi: $10.21037 / \mathrm{atm} .2018 .08 .06$

View this article at: http://dx.doi.org/10.21037/atm.2018.08.06

\section{Editor's note}

A/Prof. Brendon Yee is an honourable Editorial Board Member of Journal of Thoracic Disease (7TD, 7 Thorac Dis, pISSN: 2072-1439; eISSN: 2077-6624) and works as a senior staff specialist at Royal Prince Alfred Hospital and has been actively involved in sleep research at the Woolcock Institute of Medical Research. He has been devoted to investigating ways to improve people's sleep health since 2000. This time, we are honoured to interview A/Prof Yee to share with our readers some of his valuable experience and research findings in treating patients with sleep disorders.

\section{Expert's introduction}

A/Prof Brendon Yee MBChB FRACP PhD is a staff specialist at Royal Prince Alfred Hospital (Figure 1). He is a senior sleep and respiratory physician who heads the Sleep Investigation Unit and Respiratory Failure Services. He is a clinical associate professor at Sydney University and former clinical director and now a senior research/clinician fellow at the Woolcock Institute of Medical Research. A/Prof. Yee has a long-standing interest in the interaction between obesity, metabolic syndrome and sleep apnea, completing $\mathrm{PhD}$ in this area in 2005.

A/Professor Brendon Yee is a nationally and internationally recognized clinical researcher with a broad interest in health consequences of sleep disorders interventions and interdisciplinary care in sleep disorders. He received the Young Investigator Award at the Australasian Sleep Association Annual Meeting in 2002.

$\mathrm{He}$ was the previous Chair of the Professional Standards Committee at the Thoracic Society of Australia and New Zealand (TSANZ).

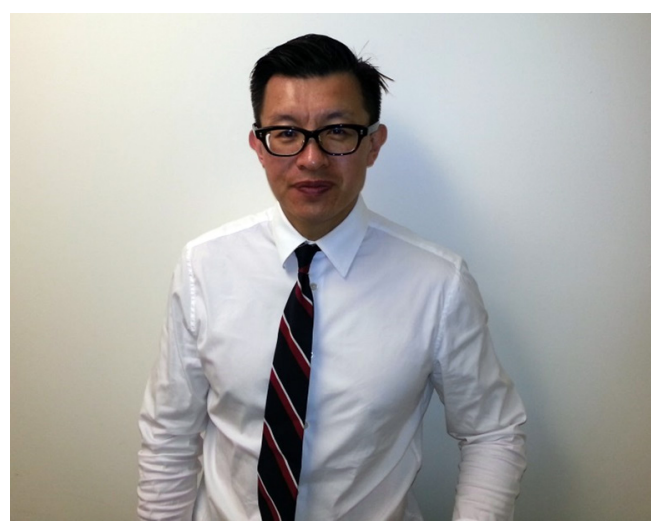

Figure 1 A/Prof. Brendon Yee.

\section{Interview}

ATM: What does your role as a staff specialist at Royal Prince Alfred (RPA) hospital involve?

A/Prof. Brendon Yee: I run the Sleep and Respiratory Failure Unit at RPA. My day-to-day role as a clinician will be involving looking after patients with a broad range of sleep disorders, including patients who have acute and chronic respiratory failure and require non-invasive ventilation.

\section{ATM: Could you briefly introduce to us the Woolcock} Institute of Medical Research? What is your scope of work bere?

A/Prof. Brendon Yee: The Woolcock Institute of Medical Research is an independent research organization, which is affiliated with the University of Sydney and RPA. It is a research organization but also provides clinical services with multidisciplinary clinics. I have worked as a senior research 
fellow here since 2001. I have been a senior research fellow/ clinician and a mentor to junior researchers.

\section{ATM: How can technology help diagnose and treat sleep disorders?}

A/Prof. Brendon Yee: Technologies are very important in sleep medicine. To diagnose sleep disorders, we attempt to apply to sleep studies by using the gold standard of laboratory sleep studies as well as portable devices. We also are looking at the detailed measurements of neurocognitive function by utilizing neurocognitive tests and high-density electroencephalography (EEG) in clinical research.

ATM: Can you briefly introduce to us the interaction between obesity, metabolic syndrome and sleep apnoea?

A/Prof. Brendon Yee: Most patients with sleep apnoea are overweight or obese. A patient with obesity and sleep apnoea is at a higher risk of developing metabolic syndrome. Thus, when treating sleep apnoea, we must treat obesity as well. That's one of the take-home messages I say to my patients. Although sleep apnoea is an independent risk factor of developing metabolic syndrome, if obesity were addressed at the same time, it can result in better cardiometabolic outcomes. Sadly, most studies have treated either sleep apnoea or obesity alone, however it is a twoway street in terms of treating obesity and sleep apnoea, and we need to address both.

\section{ATM: Is obesity commonly seen in patients with sleep apnoea?}

A/Prof. Brendon Yee: Obesity in sleep apnoea is common. In fact, we strive to organise obesity programs where we could properly supervise and motivate patients with obesity.

\section{ATM: What does interdisciplinary care in sleep disorders} involve?

A/Prof. Brendon Yee: Sleep medicine requires a lot of interactions with other specialties in treating disorders such as sleep apnoea, insomnia and narcolepsy. It may also interact with psychiatry, psychology, cardiology, ENT surgeons, dentists, endocrinologists and neurology. If you are practising sleep medicine, you need to cooperate with other specialists who have an interest in sleep disorders.
ATM: What are the common treatment methods for patients with obstructive sleep apnoea?

A/Prof. Brendon Yee: Continuous Positive Airway Pressure, or CPAP, is the gold standard for treating patients with severe sleep apnoea. However, there are many other modalities including medical and surgical weight loss therapies, dental guards, upper airway and maxilla-facial surgery.

\section{ATM: What else could we know about the diagnosis and treatment of sleep disorders?}

A/Prof. Brendon Yee: Although people can have access to information about disorders from the community, the GPs and other healthcare practitioners, there are many of sleep disorders that are not diagnosed and managed.

ATM: Are most Australians aware of the dangers of sleep disorders? How would you comment on the quality of sleep of Australians in general?

A/Prof. Brendon Yee: The awareness of sleep disorders in Australia is actually quite high. It may be reflected in the fact that there are many pioneers in sleep medicine are from Australia. Sleep medicine may not have a high-profile and may not be taught in some medical schools.

I think the quality (or quantity) of sleep in Australia maybe quite poor, like most industrialised countries. We are mostly sleep deprived, overweight, inactive and there are lot of technologies that may be interfering with our sleep.

\section{ATM: Are there any bealth policies regarding sleep disorders in Australia?}

A/Prof. Brendon Yee: There is awareness of sleep disorders in the public and policies out there to support these patients. There are government schemes to support patients with sleep related respiratory disorders with CPAP machines and non-invasive ventilation.

\section{ATM: How would you compare drug treatments and cognitive behaviour therapy (CBT) in sleep disorders?}

A/Prof. Brendon Yee: There is a lot of push in using pharmaceutical therapies for people with sleep disorders, particularly for insomnia. However, studies have shown that cognitive behaviour programs (with trained clinical psychologists) could work just as well as pharmaceutical 
therapies in patients with insomnia. I understand that people may go for medications rather than CBT because of ease and access.

\section{ATM: What would you like to do if you are not a doctor?}

A/Prof. Brendon Yee: I have a strong interest in sports, so I think I would probably be involved in sports somehow.

\section{ATM: What would be your advice to the young medical} professionals in Australia?

You have to be mindful and make sure you have a balance in

Cite this article as: Kong V. Associate Professor Brendon Yee: it is a two-way street in terms of treating obesity and sleep apnoea. Ann Transl Med 2018;6(16):328. doi: 10.21037/ atm.2018.08.06 your life as medicine can dominate your life sometimes.

\section{Acknowledgements}

We would like to express our sincerest gratitude to A/Prof. Brendon Yee for sharing his insights and opinions with us.

\section{Footnote}

Conflicts of Interest: The author has no conflicts of interest to declare.

(Science Editor: Vivian Kong, ATM, editor@atmjournal.org) 